\title{
Acute Helicobacter pylori infection: clinical features, local and systemic immune response, gastric mucosal histology, and gastric juice ascorbic acid concentrations
}

\author{
G M Sobala, J E Crabtree, M F Dixon, C J Schorah, J D Taylor, B J Rathbone, R V Heatley, \\ A T R Axon
}

\begin{abstract}
The symptomatology of a case of acute infection with Helicobacter pylori is described, together with the accompanying changes in gastric mucosal histology, local and systemic humoral immune response, and gastric ascorbic acid concentration. The patient was an endoscopist, previously negative for the carbon-14 urea breath test, who had a week of epigastric pain and then became asymptomatic. $\boldsymbol{H}$ pylori was detected by culture of antral biopsy specimens and was still present after 74 days. Five days after infection the histological findings showed acute neutrophilic gastritis; by day 74 changes of chronic gastritis were evident. The patient seroconverted by IgG enzyme linked immunosorbent assay by day 74, but a mucosal IgM and IgA response was evident as early as day 14. Infection was accompanied by a transient hypochlorhydria but a sustained fall in gastric juice ascorbic acid concentration.
\end{abstract}

It is now widely accepted that Helicobacter pylori is the cause of chronic gastritis, ${ }^{1}$ and a large proportion of the world population is chronically infected with this organism. The only descriptions of the illness accompanying the onset of infection come from two experimental ingestion studies, ${ }^{23}$ retrospectively from gastric intubation studies in which iatrogenic infection occurred, ${ }^{+567}$ and from a single case report of spontaneous infection. ${ }^{8}$ These may not be representative. We have had the serendipitous opportunity to examine in detail the symptoms, changes in local and systemic immune response, and gastric histology accompanying a further case of spontaneous infection with this organism. We have also been able to determine gastric juice ascorbic acid concentrations before and after infection. Ascorbic acid is thought to be protective against gastric cancer and is secreted by the normal stomach. This secretion is impaired in the presence of $H$ pylori associated chronic gastritis. $^{910}$

\section{Case report}

\section{CLINICAL FEATURES}

A 30 year old gastroenterology research fellow (GMS) was engaged in research which involved aspirating and handling gastric juice. $\mathrm{A}{ }^{14} \mathrm{C}$-urea breath test had been negative 2.5 years pre- viously. Over the course of an evening he developed severe epigastric pain which occurred in cramping waves lasting 15 to 30 seconds at intervals of a couple of minutes. On the first day he had mild headache and malaise but remained afebrile. He had occasional mild nausea but did not vomit. The pains woke him every night between $3.00 \mathrm{am}$ and $5.00 \mathrm{am}$. They were transiently exacerbated but then relieved by eating. The symptoms began to ease on day 5 and had completely resolved by day 7 .

\section{ENDOSCOPIC FINDINGS}

Upper gastrointestinal endoscopy on day 5 showed only gastric erythema and a gaping pylorus. Aspirated gastric juice was neutral with a $\mathrm{pH}$ of $7 \cdot 0$. On day 14 gastric erythema was still present but less pronounced, and gastric juice had a $\mathrm{pH}$ of $7 \cdot 5$. At day 74 endoscopic appearances were within normal limits, and aspirated gastric juice was acid with $\mathrm{pH} 2$.

\section{MICROBIOLOGICAL FINDINGS}

Two and a half years before the illness a ${ }^{1+} \mathrm{C}$-urea breath test had been completely negative. On day 5 a biopsy urease test (CLOtest, Delta West, Australia) was negative after one hour but positive after 24 hours' incubation, and $H$ pylori was successfully cultured although growth was scanty. On day 14 both biopsy urease test and culture were negative. At day 74 a biopsy urease test was negative but $H$ pylori was again successfully cultured. A ${ }^{13} \mathrm{C}$-urea breath test (Europa Scientific, Crewe, England) was positive at day 91 and day 342 .

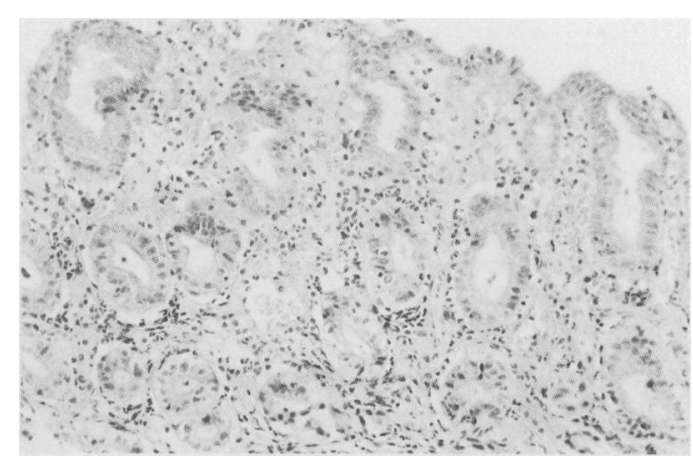

Figure 1: Antral biopsy on day 5. The lamina propria of the mucosa is infiltrated by moderate numbers of inflammatory cells largely comprising neutrophil polymorphonuclear leucocytes. These infiltrate the surface epithelium, which is appreciably degenerate and shows cellular exfoliation. Haematoxylin and eosin. Original magnification $\times 64$. 
Figure 2: Antral biopsy on day 14. While persistence of polymorphonuclear leucocyte infiltration in the lamina propria and the isthmus region of the foveolae is noted, there is now a definite increase in the numbers of lymphocytes and plasma cells propria. The epithelium is recovering its normal columnar form. Haematoxylin and eosin. Original magnification $\times 64$ in the superficial lamina

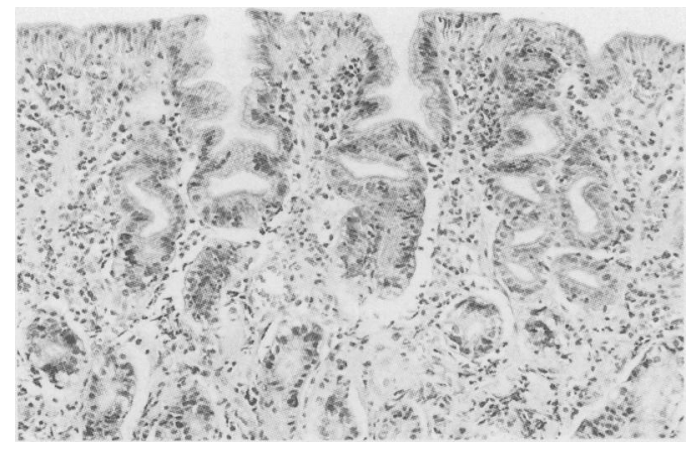

HISTOLOGICAL FINDINGS

Gastric biopsy specimens taken on day 5 showed appreciable surface epithelial degeneration with increased cell exfoliation. The superficial lamina propria contained many neutrophil polymorphonuclear leucocytes which infiltrated the surface and pit-lining epithelium and were present as a surface exudate (Fig 1). The appearances were those of an acute neutrophilic gastritis and were equally prominent in antral and body mucosa. Although a few micro-organisms including diplococci were seen in the surface exudate, no convincing helicobacters were identified with the modified Giemsa stain. Biopsy specimens from day 14 were essentially similar in showing an acute neutrophilic gastritis in antrum and body, although a minor increase in chronic inflammatory cells could be discerned (Fig 2). Again, $H$ pylori were not positively identified. Duodenal biopsy specimens were normal.

At day 74 biopsy specimens from both antrum and body showed a moderate increase in lymphocytes and plasma cells in the superficial lamina propria. There was foveolar hyperplasia and neutrophil polymorphonuclear leucocyte infiltration around the pit-isthmus region. The appearances were those of a diffuse chronic gastritis with mild activity (Fig 3). On this occasion scanty helicobacters were seen.

\section{IMMUNOLOGICAL FINDINGS}

\section{Methods}

Systemic and mucosal humoral responses to $H$ pylori were investigated by enzyme linked immunosorbent assay (ELISA) and immunoblotting. Sera were assayed for $H$ pylori IgG antibodies by ELISA using an ultracentrifuged sonicated antigen preparation from one strain of $H$ pylori. Positivity was determined by reference to $H$ pylori positive and negative control sera (ELISA sensitivity $97 \%$, specificity $95 \%$ ). Endo-

Figure 3: Antral biopsy on day 74. Small numbers of polymorphs and lymphocytes infiltrate the foveolar and surface epithelium which shows mild mucin depletion but is otherwise normal. The lamina propria shows a moderately dense infiltrate of lymphocytes and plasma cells. The appearances are those of active chronic gastritis. Haematoxylin and eosin. Original magnification $\times 64$ scopic gastric biopsy specimens on day 14 and day 74 were cultured in vitro in RPMI containing $10 \%$ fetal calf serum for three days. Biopsy culture supernatants and serum samples were analysed by Western blotting " for class specific antibodies to $H$ pylori. The $H$ pylori antigen preparation used for immunoblotting was a whole cell lysate of strain NCTC 11637.

\section{Results}

The patient was seronegative by ELISA on days 1,7 , and 14 , but was seropositive by day 74 . At day 14 antral culture supernatants were positive for $H$ pylori IgA and IgM by immunoblotting. Proteins of approximate molecular weight 31 , 40 , and $48-50 \mathrm{kDa}$ were recognised by both antral $\operatorname{IgA}$ and $\operatorname{IgM}$ antibodies. There was strong recognition of 12 and $14 \mathrm{kDa}$ antigens by the local IgM response (but not $\operatorname{IgA}$ ) on day 14 by both the antral and body mucosa. Immunoblotting of day 1,7 , and 14 sera showed no IgG recognition of $H$ pylori. There was a slight increase in serum IgM immunoblot positivity on day 14 relative to day 1 and 7 and negative control sera.

By day 74 antral culture supernatants were strongly positive for both IgM and IgA $H$ pylori antibodies by immunoblotting but no mucosal IgG response was evident. Additional $H$ pylori antigens recognised by both $\operatorname{IgA}$ and $\operatorname{IgM}$ at 74 days included proteins of approximate molecular weight $90,60,44$, and $25 \mathrm{kDA}$. Recognition of a $120 \mathrm{kDa}$ protein by the mucosal IgA response was evident by day 74 . Immunoblotting of concurrent serum showed IgM and IgG recognition of a $120 \mathrm{kDa}$ protein but no strong recognition of other $H$ pylori proteins. Serum at day 138 showed similar reactivity to day 74 in IgG and IgM immunoblots. No systemic IgA response was evident by immunoblotting. By day 198 a serum IgG response against additional proteins between 40 to $50 \mathrm{kDa}, 70$ to $85 \mathrm{kDa}$, and at $90 \mathrm{kDa}$ was evident.

\section{GASTRIC JUICE ASCORBIC ACID}

\section{Method}

Ascorbic acid and its oxidation product dehydroascorbic acid together comprise total vitamin C. Only ascorbic acid is an antioxidant, although both compounds are antiscorbutic. The concentrations of ascorbic acid and total vitamin $C$ in gastric juice were determined at each endoscopy and also three times by nasogastric intubation, 170 days before and 37 and 161 days after the start of the clinical illness. On these occasions a nasogastric tube was passed in the morning after an overnight fast and was placed on continuous suction. The volume of gastric juice aspirated every 15 minutes for at least 90 minutes was measured, the gastric juice $\mathrm{pH}$ was determined, and a $1 \mathrm{ml}$ aliquot of juice was put straight into $1 \mathrm{ml}$ of a $2 \%$ solution of metaphosphoric acid and frozen at $-70^{\circ} \mathrm{C}$. An intravenous injection of $500 \mathrm{mg}$ of ascorbic acid was given at 45 minutes. On the first occasion blood was drawn into a heparinised container before and 90 minutes after the injection, while 
Fasting gastric juice $p H$ (spot value, or median and range of a series), mean fasting gastric juice ascorbic acid, and total vitamin $C$ concentrations, plasma total vitamin $C$ concentrations, and total recovery of ascorbic acid and total vitamin $C$ from gastric juice in 45 minutes after an intravenous injection of $500 \mathrm{mg}$ ascorbic acid on five occasions ranging from approximately fou months before to five months after acute $\mathrm{H}$ pylori infection. Gastric juice was obtained either by nasogastric intubation for at least 90 minutes or at endoscopy

\begin{tabular}{|c|c|c|c|c|c|}
\hline & \multicolumn{5}{|c|}{ Fuice obtained by: } \\
\hline & Tube & Endoscopy & Tube & Endoscopy & Tube \\
\hline $\begin{array}{l}\text { Time in relation to onset of infection } \\
\text { (days) } \\
\mathrm{pH}\end{array}$ & $\begin{array}{c}-170 \\
2 \cdot 0 \\
(1 \cdot 5-4 \cdot 5)\end{array}$ & $\begin{array}{r}+14 \\
7 \cdot 5\end{array}$ & $\begin{array}{l}+37 \\
7 \cdot 5 \\
(7 \cdot 0-8 \cdot 0)\end{array}$ & $\begin{array}{r}+74 \\
2 \cdot 0\end{array}$ & $\begin{array}{c}+161 \\
2 \cdot 3 \\
(1 \cdot 9-7 \cdot 6)\end{array}$ \\
\hline $\begin{array}{l}\text { Gastric juice ascorbic acid }(\mu \mathrm{mol} / \mathrm{l}) \\
\text { Gastric juice total vitamin } C(\mu \mathrm{mol} / \mathrm{l}) \\
\text { Plasma total vitamin } C(\mu \mathrm{mol} / \mathrm{l}) \\
\text { Ascorbic acid recovery }(\mu \mathrm{g}) \\
\text { Total vitamin } C \text { recovery }(\mu \mathrm{g})\end{array}$ & $\begin{array}{r}22 \\
37 \\
35 \\
1862 \\
1872\end{array}$ & $\begin{array}{l}5 \\
5 \\
- \\
- \\
-\end{array}$ & $\begin{array}{r}1 \\
2 \\
30 \\
9 \\
109\end{array}$ & $\begin{array}{l}1 \\
9 \\
- \\
-\end{array}$ & $\begin{array}{r}2 \\
8 \\
53 \\
292 \\
330\end{array}$ \\
\hline
\end{tabular}

on the last two occasions it was drawn at 15 minute intervals throughout the procedure and also three minutes after injection. After centrifugation, $1 \mathrm{ml}$ of plasma was added to $2 \mathrm{ml}$ of $2 \%$ metaphosphoric acid and frozen at $-70^{\circ} \mathrm{C}$. Gastric juice and plasma samples were then analysed within two weeks for ascorbic acid and total vitamin $\mathrm{C}$ concentrations using a previously developed high performance liquid chromatography method.

\section{Results}

Before the illness fasting gastric juice ascorbic acid and total vitamin $C$ concentrations were approximately equal to plasma, and rose rapidly after intravenous ascorbic acid (Table, Fig 4). At 37 days ascorbic acid was scarcely detectable in gastric juice either fasting or after injection, although a small amount of total vitamin $C$ was recovered from gastric juice after injection (Table). Gastric juice $\mathrm{pH}$ remained neutra throughout. At 161 days gastric juice was once more of acid $\mathrm{pH}$ but both ascorbic acid and total vitamin $\mathrm{C}$ concentrations remained low and rose only slightly after intravenous ascorbic acid (Table, Fig 4).

\section{Discussion}

Figure 4: Gastric juice ascorbic acid concentrations before and after intravenous injection of $500 \mathrm{mg}$ ascorbic acid, 170 days before and 37 and 161 days after acute $\mathrm{H}$ pylori infection.

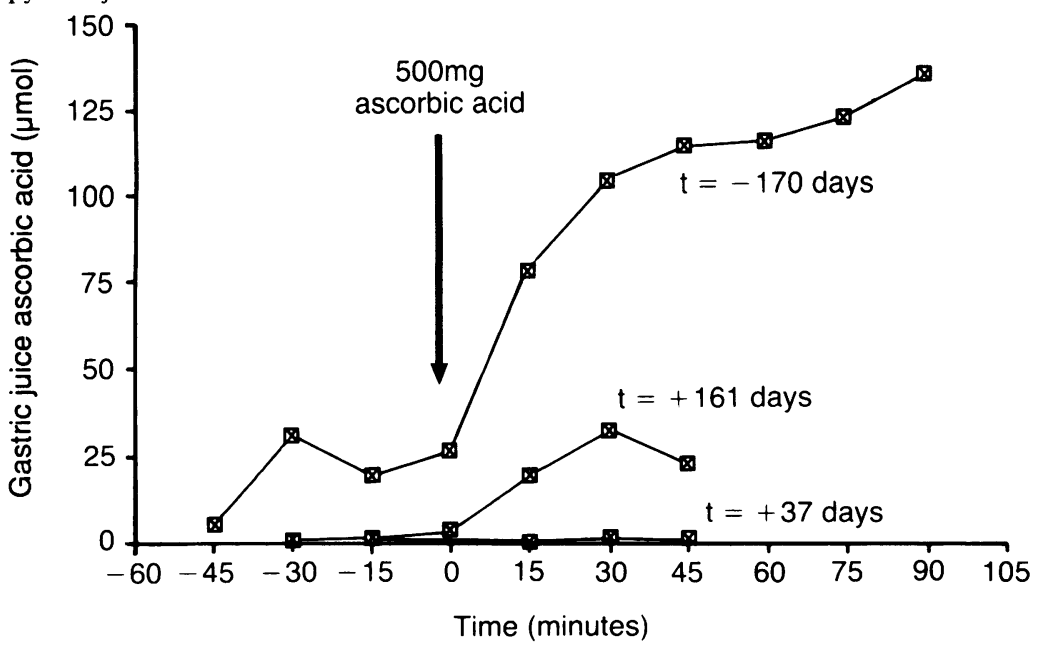

ponded to acute infection with $H$ pylori. There is no doubt that the patient was ultimately positive for $H$ pylori, as it was detected by several techniques. It could be argued that the symptomatic illness and hypochlorhydria were due to another unidentified aetiological factor, which allowed colonisation by $H$ pylori. This suggestion is impossible to refute but on the basis of Occam's razor it is unnecessary. Firstly, the association between $H$ pylori and chronic gastritis cannot be doubted and elimination of the organism results in healing of gastritis. ${ }^{12}$ Secondly, the symptoms closely resembled those described by Arthur Morris after voluntary ingestion of $H$ pylori, ${ }^{3}$ and were broadly similar to those of Barry Marshall. ${ }^{2}$ Arthur Morris also experienced hypochlorhydria and developed chronic gastritis. Thus we have described no phenomena that require additional hypothetical causes.

We propose that at least some people who are acutely infected with $H$ pylori experience a brief self limiting episode of dyspepsia: certainly about $60 \%$ of patients infected iatrogenically became symptomatic. It is not surprising, however, that this syndrome has not been clinically recognised before, as by the time such patients are referred their symptoms will have settled, and the endoscopic appearances would not be especially remarkable in those who are investigated. If looked for hard enough further cases may come to light. For example, we have recently seen a 20 year old woman who required admission to hospital because of severe cramping epigastric pains lasting one week. Although endoscopy on day 7 was unremarkable, the fasting gastric juice was of neutral $\mathrm{pH}$, and gastric biopsy specimens showed histological appearances of $H$ pylori positive acute neutrophilic gastritis identical to that described above. Thus we believe that acute $H$ pylori injection should now be considered in the differential diagnosis of acute epigastric pain.

A recent study has shown a high incidence of $H$ pylori positive serology in endoscopy staff,, 13 and it is likely that our patient became infected either by inhalation of spray from the biopsy channel of a fibre endoscope or while handling gastric juice samples for research. His wife was seronegative by ELISA for $H$ pylori.

The histological features early in the illness were unusual and distinctive. Acute gastritis is usually seen in the context of non-steroidal antiinflammatory drug use or excessive alcohol. ingestion and presents histologically as an erosive or haemorrhagic gastritis with epithelial degeneration, foveolar hyperplasia, oedema and congestion of the lamina propria, and interstitial haemorrhage. Neutrophil polymorphonuclear leucocytes (and other inflammatory cells) are scanty or absent. The finding of conspicuous infiltration in acute $H$ pylori infection distinguishes the mucosal response from that seen in drug or alcohol related injury.

Acute neutrophilic gastritis is rarely found in endoscopic biopsies. In the pre- $H$ pylori era it was a recognised response to other bacterial infections of the stomach, but these were largely confined to severely debilitated patients and at necropsy as a suppurative or 'phlegmonous' gastritis principally of the submucosal layer of 
the stomach wall. ${ }^{15} \mathrm{H}$ pylori has been incriminated in an acute 'purulent' gastritis, ${ }^{16}$ but up to now the only histological description of the early response to proven infection is contained in the reports of Marshall $e t a l^{2}$ and Morris and Nicholson. ${ }^{3}$ This is the first detailed account of the appearances after a 'naturally' acquired infection with $H$ pylori.

It is notable that early in the illness it was not easy to positively identify $H$ pylori by several different techniques, and this difficulty may be related to the transient hypochlorhydria. It seems that $H$ pylori survives but does not flourish in the stomach when gastric juice is of neutral $\mathrm{pH}$ : this is evident in patients treated with omeprazole, which suppresses but does not eradicate the organism. ${ }^{17} 18$

Immunoblotting showed that a local immune response to $H$ pylori was evident in this subject soon after the onset of symptoms, at which time there was no evidence of a systemic IgG response to $H$ pylori by either immunoblotting or ELISA. The strong local IgM response on day 14 is compatible with an acute infection. The persistence of the mucosal $\operatorname{IgM}$ response at 74 days is of interest as there is little evidence of a specific antral IgM response by immunoblotting in patients with chronic gastritis (J Crabtree, unpublished observations), such patients having a strong local IgA response to $H$ pylori. ${ }^{19}$ The occurrence of a rapid local immune response after the onset of symptoms reinforces a pathogenic role for $H$ pylori.

The first major $H$ pylori antigen recognised systemically by $\mathrm{IgG}$ was the $120 \mathrm{kDa}$ protein. This protein is thought to be a surface protein and is not present in all $H$ pylori strains. ${ }^{20}$ The increased systemic IgG recognition of $H$ pylori proteins between days 138 and 198 in this subject shows that serological responses to $H$ pylori take time to develop fully.

We have previously shown that many people with normal gastric histology have high concentrations of ascorbic acid in gastric juice, but that intragastric concentrations are much lower in patients with $H$ pylori associated chronic gastritis. $^{910}$ Preinfection fasting intragastric concentrations in this patient were only approximately equal to and not greater than plasma concentrations, but we have observed this in other normal subjects. ${ }^{9}$ Intragastric concentration rose rapidly after intravenous injection. However, 37 days after infection during the hypochlorhydric phase there was virtually no ascorbic acid or total vitamin $\mathrm{C}$ in the stomach either in the fasting state or after the intravenous supplementation. Although ascorbic acid is relatively unstable in neutral gastric juice this is only because of its rapid oxidation to dehydroascorbic acid, and we have shown that in vitro virtually $100 \%$ of ascorbic acid added to neutral gastric juice can be recovered as total vitamin $C$ after an incubation period of one hour, most of it by then in the form of dehydroascorbic acid. ${ }^{21}$ That $H$ pylori associated gastritis represents a failure of secretion and not merely $\mathrm{pH}$ dependent destruction of ascorbic acid is confirmed by the fact that gastric juice ascorbic acid concentration remained low and incremented poorly even when recovery from hypochlorhydria had occurred at 161 days. Initially the poor ascorbic acid secretion was paralleled by a failure of hydrogen ion secretion, but there is evidence that the two secretory mechanisms are independent ${ }^{21}$ and this is supported by the findings here at 161 days.

There is some evidence that $H$ pylori does not tolerate high ascorbic acid concentrations well, ${ }^{22}$ and thus a reduction of ascorbic acid concentration in the stomach may favour its survival. The effect on the host is to decrease antioxidant potential in gastric juice and remove a putative protective factor against gastric cancer. This may be an important factor in the association between chronic gastritis and gastric cancer.

We conclude that infection with $H$ pylori gives rise to a distinctive syndrome of cramping epigastric hunger pains which are accompanied by a transient fasting achlorhydria and a characteristic histological picture of acute neutrophilic gastritis. The organism may be difficult to find during the period of hypochlorhydria. The symptoms are self limiting, but infection may become chronic and is accompanied by first a local and then a systemic immune response. Gastric antioxidant defences in the form of gastric juice ascorbic acid are impaired.

1 Dixon MF. Campylobacter pylori and chronic gastritis. In: Rathbone BJ, Heatley RV, eds. Campylobacter pylori and
gastroduodenal disease. Oxford: Blackwell, 1989: 106-16.

2 Marshall B, Armstrong J, McGechie D, Glancy R. Attempt to fulfill Koch's postulates for pyloric Campylobacter. Med f Aust 1985; 142: 436-9.

3 Morris A, Nicholson G. Ingestion of Campylobacter pyloridis causes gastritis and raised fasting gastric $\mathrm{pH}$. Am $\mathcal{F}$ Gastroenterol 1987; 82: 192-9.

4 Ramsey EJ, Carey KV, Peterson WL, et al. Epidemic gastritis with hypochlorhydria. Gastroenterology 1979; 76: 1449-57.

Peterson WL, Lee E, Skogland M. The role of Campylobacter pyloridis in epidemic gastritis with hypochlorhydria. Gastropyloridis in epidemic gas

6 Gledhill T, Leicester RJ, Addis B, et al. Epidemic hypochlorhydria. $B M \mathcal{F} 1985$; 289: 1383-6.

7 Graham DY, Alpert LC, Smith JL, Yoshimura HH. Iatrogenic Campylobacter pylori infection is a cause of epidemic achlorhydria. Am $\mathcal{f}$ Gastroenterol 1988; 83: 974-80.

8 Frommer DJ, Carrick J, Lee A, Hazell S. Acute presentation of Campylobacter pylori gastritis. Am $\mathcal{F}$ Gastroenterol 1988; 83: $1168-71$.

9 Sobala GM, Schorah CJ, Sanderson M, et al. Ascorbic acid in the human stomach. Gastroenterology 1989; 97: 357-63.

10 Rathbone BJ, Johnson AW, Wyatt JI, Kelleher J, Heatley RV Losowsky MS. Ascorbic acid: a factor concentrated in human gastric juice. Clin Sci 1989; 76: 237-41.

11 Blake MS, Johnstone KH, Russell-Jones GJ, Gotschlich EC. A rapid, sensitive method for detection of alkaline phosphatase-conjugated anti-antibody on Western blots. Anal Biochem 1984; 136: 175-9.

12 Rauws EAJ, Langenberg W, Houthoff $\mathrm{HJ}$, Zanen HC, Tytgat GNJ. Campylobacter pyloridis-associated chronic active antral gastritis. Gastroenterology 1988; 94 : 33-40.

13 Mitchell HM, Lee A. Carrick JTI. Increased incidence of Campylobacter pylori infection in gastroenterologists: further evidence to support person-to-person transmission of evidence to support person-to-person trans

14 Reiff A, Jacobs E, Kist M. Seroepidemiological study of the immune response to Campylobacter pylori in potential risk groups. Eur F Clin Microbiol Infect Dis 1989; 8: 592-6.

15 Miller AI, Smith B, Rogers AI. phlegmonous gastritis. Gastroenterology 1975; 68: 231-8.

16 Salmeron M, Desplaces N, Lavergne A, Houdart R. Campylobacter-like organisms and acute purulent gastritis. Lancet 1986; ii: 975-6.

17 Unge P, Gad H, Gnarpe H, Olsson J. Does omeprazole improve antimicrobial therapy directed towards gastric study. Scand f Gastroenterol 1989; 24 (suppl 167): 49-54.

18 Stolte $M$, Bethke B. Elimination of Helicobacter pylori under treatment with omeprazole. Z Gastroenterol 1990;28: 271-4

19 Crabtree JE, Taylor JD, Shallcross TM, Rathbone BJ Heatley RV. Immunoblotting of Helicobacter pylori IgA antibody response in gastroduodenal mucosa. Gut 1990; 31

20 Apel I, Jacobs E, Kist M, Bredt W. Antibody response of patients against a $120 \mathrm{kDa}$ surface protein of Campylobacter pylori. Zentralblatt fur Bakteriologie, Mikrobiologie und Hygiene A 1988; 268: 271-6.

21 Schorah CJ, Sobala GM, Sanderson M, Collis N, Primrose JN Gastric juice ascorbic acid: effects of disease and implications for gastric carcinogenesis. Am F Clin Nutr 1991; 53: 287S93S

22 Goldie J, Jalali S, Van Zanten S, Stowe C, Hunt RH. Ascorbic acid inhibits the growth and urease activity of Campylobacter pylori. Gut 1989; 30: Al 1484. 